\title{
EVALUATION OF THREE COMMON DENTURE CLEANERS
}

\author{
A. Margo. Evaluation of three common denture \\ cleaners. Annal Dent Univ Malaya 2003; 10: 38-42.
}

\author{
A. Margo \\ Prosthodontic Department, \\ Faculty of Dentistry, Trisakti University, \\ Grogol, Jakarta Barat 11440, \\ Indonesia \\ Corresponding author - Anton Margo
}

Plaque is responsible for variety of soft tissue changes in many denture wearers (3-4). These changes manifest themselves as a series of related symptom complexes which include denture stomatitis, inflammatory papillary hyperplasia, and chronic candidiasis. Ill-fitting dentures, trauma, and lack of denture cleanliness are most commonly cited triad of local etiologic factors for each of these entities and the plaque that forms on the tissue surfaces probably is of the greatest clinical significance (4).

Budt-Jorgensen and Bertram (5) found stomatitis in 58 patients with complete dentures and compared them to a control group with complete dentures and clinically normal palatal mucosa. They found that denture cleanliness was far better in control group than in the denture with stomatitis group and there was a statistically significant relationship found between poor denture cleanliness and severe inflammation. In a series of reports dealing with denture stomatitis, Olsen (6-8) came to the conclusion that disinfection of the denture is the essential preventive procedure, because the bulk of causative microorganism reside on the denture base. Tarbet (9) in 1982 reported relationship between mucosa health improvements and the reduction in denture plaque by a rigorous denture hygiene program.

Proper routine cleaning of tissue surface of a denture is essential to maintain healthy supporting tissues (9). To be effective, a denture cleaner must be capable of removing plaque from not only the polished surfaces of the prosthesis but more importantly the unpolished tissue surface of the denture (10). It is at this interface that the plaque accumulating on the denture causes denture stomatitis, inflammatory papillary hyperplasia and chronic candidiasis $(4,11)$.

The most common method of routine denture cleaning is brushing with tap water and either soap or toothpaste. Tarbet (11) (1982) reported that fifty percent of his study subjects used a paste and brush to clean their denture regularly. A number of recently developed toothpastes and liquid soaps are used to clean dentures, but the efficiency of these materials in denture plaque removal is not supported by substantial experimental evidence. 
In this study, two common cleaning agents and a toothpaste used as denture cleaners were evaluated by use of toothbrush in removal of denture plaque. The specific aim of this study was to compare the effectiveness of these common denture cleaners in removal of accumulated plaque from the tissue surface of maxillary complete dentures.

\section{MATERIALS AND METHODS}

Fourteen healthy edentulous patients ranging from 55 to 79 years of age with a mean of $64.50 \pm 8.01$ years were randomly selected from twenty one subjects. Complete dentures were made for each patient by the students at Department of Prosthodontics, Faculty of Dentistry, Trisakti University. After completion of the necessary adjustments, all the maxillary dentures were ultrasonically cleaned for 30 minutes to perform a uniform baseline.

The subjects were divided into control group $(\mathrm{n}=$ 6) and treatment group ( $\mathrm{n}=8$ ). The subjects of control group were then informed that they would be required one test session to clean their denture with a wet brush. Subjects of the treatment group were informed that they would be required for three test sessions. They were also informed that they should not clean and remove their dentures in any manner for 3 days prior the test session, thereby providing a substantial, general reproducible buildup of plaque.

At the test session, the maxillary dentures with 3 days of accumulation of plaque were coded and rinsed in flow controlled running water (1000 cc / minute) for 1 minute to remove any loose food debris.

The mercurochrome $(4,5 \%)$ dye (Table 1$)$ was then dropped on the tissue surface of the maxillary dentures to disclose bacterial plaque for 1 minute. Excess dye was gently rinsed in flow controlled running water for 1 minute.

Plaque accumulation were scored according to the plaque index usually used for evaluation of commercial denture cleaner products $(1,12)$ and is as follows:

The tissue surface of each maxillary denture was divided into four sections approximately equal in area by drawing a line anteroposteriorly at the midline and another line perpendicular to the midline at about the distal second premolar region. Plaque was disclosed with mercurochrome dye (Fig. 1) and each of these quadrants was scored before each regimen (Fig. 2 and $3)$, as follows: $1=$ no plaque; $2=$ light plaque $(25 \%$ or less of the quadrant); $3=$ moderate plaque $(26 \%$ to $50 \%$ of the quadrant covered); $4=$ heavy plaque ( $51 \%$ to $75 \%$ of the quadrant covered); and $5=$ very heavy plaque ( $76 \%$ to $100 \%$ of the quadrant covered). This was done by two separate investigators and the results were tabulated. A total denture plaque score of both control group and treatment group were obtained by summing the quadrant scores.

After the scoring was done, the tissue surface of each maxillary denture of control group was tested

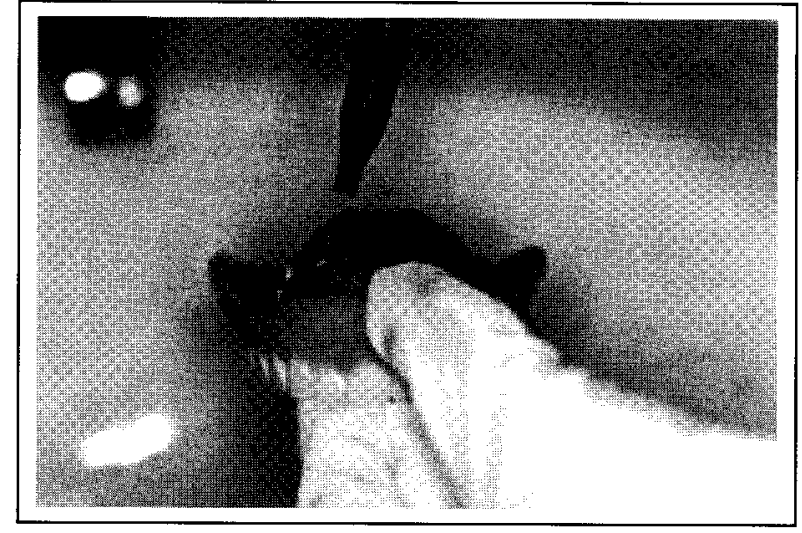

Figure 1: Disclosing medium applied to the tissue surface of maxillary denture

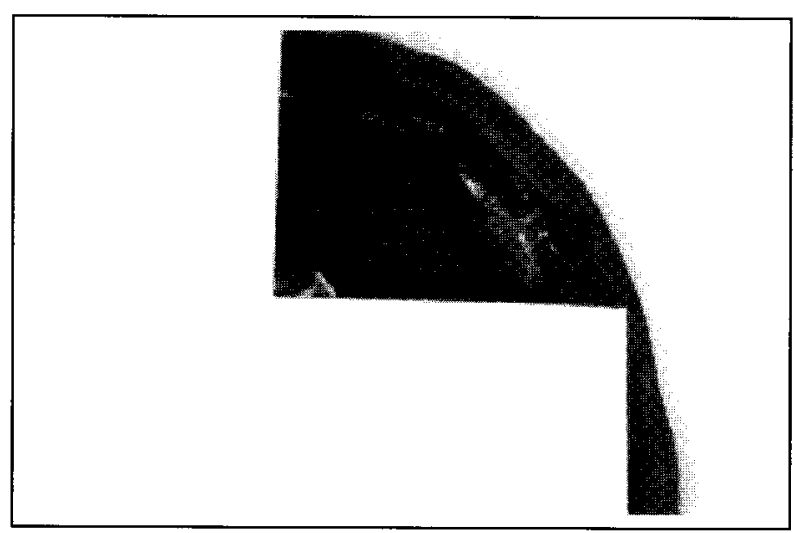

Figure 2: Scoring denture plaque

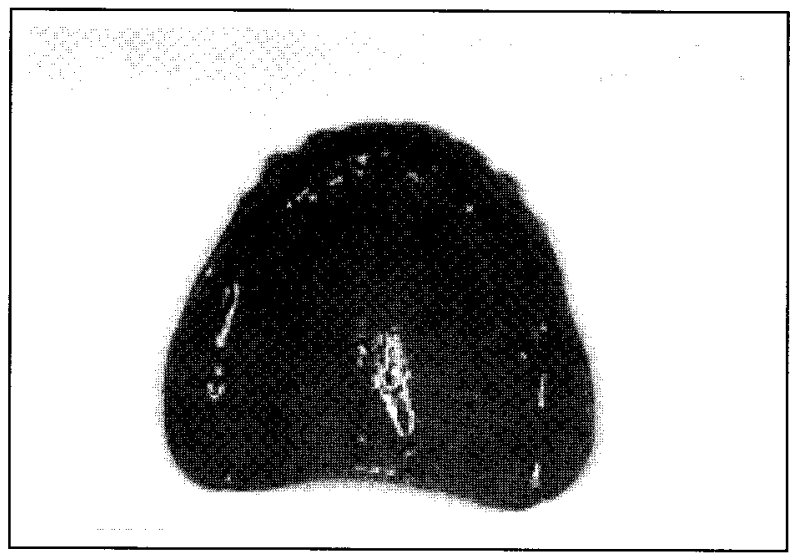

Figure 3: Denture plaque before tretment

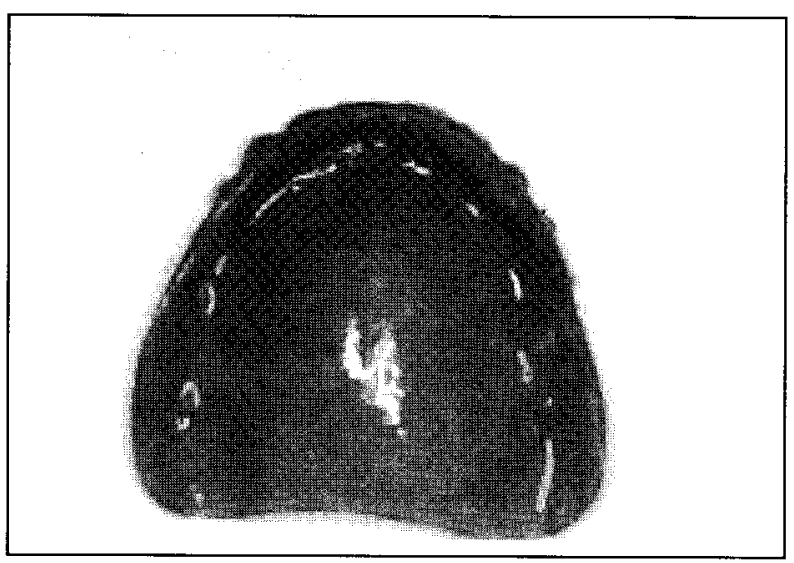

Figure 4: Denture plaque after treatment 
Table 1. Materials used in this test

Materials
Soft toothbrush
Toothpaste
Hand washing liquid soap
Bar mild bathsoap
Ultra sonic cleaner
Disclosing solution

using a wet toothbrush (Table I), and the tissue surface of each maxillary denture of the treatment group was also tested with the first regimen, consisting of the use of wet toothbrush and toothpaste (Table 1). A mechanical hand brushing method was carried out anteroposterioly for cleaning thoroughly the entire tissue surface of the maxillary dentures (80 times/ minute) for 1 minute by the same operator. After the tissue surface of maxillary dentures has been cleaned according to the prescribed introduction, the tissue surface of maxillary dentures were rinsed in flow controlled running water for I minute to remove the residue of the toothpaste. The mercurochrome dye was then dropped on the tissue surface of the dentures to disclose bacterial plaque for 1 minute and the excess dye was gently rinsed in flow controlled running water for 1 minute (Fig. 4). Scores of both control group and treatment group were once again recorded to give post-cleaning plaque values.

The dentures of the treatment group were then ultrasonically cleaned again for 30 minutes and the patients were reappointed for the next test session with the second and third regimens test. The length of time between each session was 3 days. The quantity of each denture cleaner applied on to the wet toothbrush in this study was as follows: 1) about $15 \mathrm{~mm}$ of toothpaste, 2) one pushing drop of hand washing liquid soap and 3) one scraping of soaked bar mild bath soap (Table 1).

The denture plaque score before and after treatment of the control group and within the treatment groups were given as means and standard deviation, and the plaque score change before and after treatment was also analyzed with paired Student t-test. The differences in mean plaque score after treatment between the three treatment groups were statistically analyzed by a one-way analysis of variance. If the differences at $\mathrm{p}<0.05$ level were found, the treatment comparisons were done by Tukey HSD multiple comparisons test. Data in this study was analyzed using SSP 11.00 program.
Manufactured by

Active ingredient

Ultra Prima Abadi, Indonesia

Unilever Co, Indonesia

$0.32 \%$ Sodium Fluoride, $0.75 \%$ Zinc Citrate

$0.3 \%$ Triclosan

Kienoes I Kamulya Co, Indonesia

Alkaline based

Unilever Co, Indonesia

Alkaline based

Ivoclar, Liechtenstein

water

Periodontic Dept, Usakti

$4,5 \%$ Mercurochrome

\section{RESULTS}

Table 2 and 3 showed the mean and standard deviation value of denture plaque scores before and after treatment of the control and treatment group. Statistical analysis accomplished using the paired Student t-test, revealed no statistical significance $(p=0.061)$ for the control group, but within the treatment groups there is a highly statistically significant difference in the mean score before and after for all treatment groups $(\mathrm{p}=0.000) \quad$ (Table 3).

The statiscal analysis of denture plaque scores after treatment using the one-way analysis variance, revealed a statistically significant $(\mathrm{p}<0.05)$ difference between the three groups (Table 4). Application of Tukey's HSD multiple comparisons test also revealed a statistically significant difference between toothpaste and hand washing liquid soap $(p<0.05)$ (Table 5). There was no significant difference between hand washing liquid soap and bar mild bathsoap ( $p>0.05$ ), and between toothpaste and bar mild bath soap $(p>0.05)$ (Table 5). The results of this study showed that denture plaque removing effectiveness of brushing with hand washing liquid soap was substantially greater than bar mild bath soap or toothpaste (Table 6 ).

\section{DISCUSSION}

Although there are many commercial denture cleaner products, they are not widely promoted by many manufacturers as being done for toothpastes. Another reason is that, these products are not easily available in the Indonesian market. They are also too expensive

Table 2. Mean and standard deviation plague scores control group were analyzed with paired Student t-test

$\begin{array}{lccccc}\text { Brushing } & \mathrm{n} & \text { Mean } \pm \text { SD } & \text { df } & & \text { Sig } \\ \text { Before } & 6 & 17.167 \pm 2.041 & 5 & 20,402 & 0.061 \\ \text { After } & 6 & 16.718 \pm 1.900 & & & \end{array}$


Table 3. Mean and standard deviation plaque scores within treatment groups were analyzed with paired Student t-test.

\begin{tabular}{|c|c|c|c|c|c|}
\hline Group & $\begin{array}{c}\text { Prior } \\
\text { Mean } \pm \text { S.D. }\end{array}$ & $\begin{array}{c}\text { After } \\
\text { Mean } \pm \text { S.D. }\end{array}$ & $\mathrm{df}$ & & Sig \\
\hline Toothpaste & $15.500 \pm 3.664$ & $8.458 \pm 3.216$ & 7 & 6.323 & $0.000^{\prime \prime}$ \\
\hline Liquid soap & $15.125 \pm 3.758$ & $4.500 \pm 2.777$ & 7 & 14.409 & $0.000^{\prime \prime}$ \\
\hline Bathsoap & $14.750 \pm 2.816$ & $7.666 \pm 2.570$ & 7 & 12.595 & $0.000^{\prime \prime}$ \\
\hline
\end{tabular}

Table 4. Analysis of variance of denture plaque scores treatment group after treatment

$\begin{array}{lrrrrr} & \begin{array}{c}\text { Sum of } \\ \text { Squares }\end{array} & \text { df } & \begin{array}{c}\text { Mean } \\ \text { Square }\end{array} & F & \text { Sig. } \\ \text { Between groups } & 70.136 & 2 & 35.068 & 4.267 & \overline{0.028^{\prime}} \\ \text { Within groups } & 172.575 & 21 & 8.218 & & \\ \text { Total } & 242.711 & 23 & & & \\ , p<0.05 & & & & & \end{array}$

Table 5. Summary of multiple comparisons treatment between treatment groups were analyzed by Tukey's HSD

$\begin{array}{lccc}\text { Between groups } & \begin{array}{c}\text { Mean } \\ \text { difference }\end{array} & \begin{array}{c}\text { Std. } \\ \text { Error }\end{array} & \text { Sig. } \\ \text { Toothpaste - Liquid soap } & 3.956 \text { ' } & 1.433 & 0.030 \\ \text { Toothpaste - bath soap } & 0.790 & 1.433 & 0.847 \\ \text { Liquid soap - bathsoap } & -3.166 & 1.433 & 0.093 \\ \text { 'The mean differences is significant } & \text { at the } .05 \text { level } & & \end{array}$

Table 6. Subset for alpha $=0.05$

$\begin{array}{lll}\text { Group } & \text { N } & \text { Subset } \\ \text { Liquid soap } & 8 & 4.500 \\ \text { Bathsoap } & 8 & 7.666 \\ \text { Toothpaste } & 8 & 8.458\end{array}$

for most of the geriatric complete denture wearers. Data from the patients in this study reported that they brush their dentures using toothbrush with toothpaste (50\%), liquid soap $(25 \%)$ and bar mild bath soap $(25 \%)$ to regularly clean their dentures.

In this study, the control group showed that brushing denture with a soft wet toothbrush alone could not clean the denture effectivelly. Some authors suggested the use of hard toothbrush, by increasing diameter of the bristle and decreasing the length of the bristle, but this toothbrush causes wear of the
Patients prefer to use toothbrush with toothpaste to clean their dentures for two reasons. First, the present paramount concern to the patient is the social or cosmetic aspect of cleansing, and the second is the need to thoroughly remove denture plaque at regular intervals, especially on the tissue surface of the dentures (11).

It is apparent from the results of this study that brushing with toothpaste or soaps, either a bar soap, or liquid soap, can significantly remove accumulated denture plaque. This observation supports the findings of Tarbet et al (9) and Abelson (12) that paste/brushing method was consistently the more effective procedure for removal of denture plaque compared to soak type denture cleaning method.

Non-ionic and anionic antimicrobial agent (14-17) have been shown to reduce plaque formation more effectively than abrasive agents. This cross sectional study showed that the denture plaque removal by brushing using toothpaste was less effective than brushing using bar mild bath soap or liquid soap. This conformed to the previous study that the antiplaque action of these non-ionic and/or anionic substances are by their/its antimicrobial spectrum, together with their/ its affinity for intraoral surfaces, and subsequently prolonged time of retention and activity, make them/ it useful as an antiplaque agent (18-21).

Soaps either potassium or sodium become alkaline solution when dissolved in water. These type of cleaners are usually alkaline detergents that can reduce surface tension and combines with mechanical brushing support the cleansing effect and their activity is increased at the higher $\mathrm{pH}$. The liquid soap can dissolve in water more easily and quickly. This conforms that the denture plaque removing effectiveness of brushing with liquid soap tested was found to be substantially greater than brushing with a bar bath soap or a toothpaste. Although liquid soap until now has not been promoted as a denture cleaner, it can be used effectively as denture plaque reducing agent.

In conclusion, this study seems to verify that brushing with a toothpaste, a bar mild bath soap or a liquid soap is effective in reducing denture plaque, and liquid soap is more effective than bar soap or toothpaste. It can be recommended that liquid soap is 


\section{REFERENCES}

1. Augsburger, R.H. and Elahi, LM. Evaluation of seven propriety denture cleaners. J Prost Dent. 1982; 47: 356-9.

2. MacCallum, M., Stafford, G.D. and MacCulloch, W.T. Which cleaner? A report on a survey of denture cleaning routine and development of a new denture cleaner. Dent Practit 1968; 19: 83-8.

3. Love, W., Coska, F. and Minon, R. The etiology of mucosa inflammation associated with dentures. J Prosthet Dent 1967; 18: 515-9.

4. Abelson, D.C. Denture plaque and denture cleaner. J Prosthet Dent 1981; 45: 376-379.

5. Budt-Jorgensen, E. and Bertram, U. Denture stomatitis. I. The etiology in relation to trauma and infection. Acta Odontol Scand 1970; 28: 714.

6. Olsen, I. Denture stomatitis: occurrence and distribution of fungi. Acta Odontol Scan 1974; 32: 329-34.

7. Olsen, I. Denture stomatitis: Denture stomatitis, effect of chlohexidine and amphotericin B on the mycotic flora. Acta Odontol Scand 1975; 33: 4146.

8. Olsen, I. Denture stomatitis, relapse tendency and removal of acquire dicoloration in long term denure infection with chlorhexidine. Acta Odontol Scand 1975; 33: 111-5.

9. Tarbet, W.J., Axelrod, S., Minkoff, S. and Fratarcangelo, P.A. Denture cleaning: A comparison of two methods. J Prosthet Dent 1984; 51: 322-5.

10. Keenan, M.o., Shillingburg, H.T., Duncan, M.G. and Wade, C.K. Effects of cast gold surface finishing on plaque retention. J Prosthet Dent 1981; 43: 168-73.

11. Tarbet, W.J. Denture plaque: Quite destroyer. J Prosthet Dent 1982; 48: 647-52.
12. Abelson, D.C. Denture plaque and denture cleaners. 1981 ; 45: 376-379.

13. Budt-Jorgensen, E. Materilas and methods for cleaning dentures. J Proshet Dent 1979; 42: 61923.

14. Renvert, S. and Birkhed, D. Comparisons between 3 triclosan dentifrices on plaque, gingivitis and salivary microflora. J Clin Periodontol 1995; 22: 63-70.

15. Bradshaw, D.J., Marsh, P.D., Watson, G.K. and Cummins, D. The effects of Triclosan dan zinc citrate, alone and in combination, on a community of oral bacteria grown in vitro. J Dent Res 1993; 72: $25-9$.

16. Zambon, J.J., Reynolds, H.S., Dunford, RG. and Bonta, C.Y. Effect of a triclosan/copolymer/ fluoride dentifrice on th oral microflora. Am $\mathbf{J}$ Dent 3 (special issue), 1990; 27-33.

17. Jone, C.L., Ritchie, LA., Marsh, P.D. and van der Ouderaa, F. The effect of long-term use of dentifrice containing zinc citrate and a non-ionic agent on the flora. J Dent Res, 1988; 67: 46-50.

18. Bonesvoll, P. and Gjeermo, P. A Comparison between chlorhexidine and some quaternary symmonium compounds with regard to retension, salivary consentration and plaque-inhibiting effect in the human oral cavity after mouthrises Arch Oral Bio 1978; 23: 289-94.

19. Cummins, D. Zinc citrate/Triclosan: a new antiplaque system for control of plaque and the prevention of gingivitis: short-term clinical and mode action studies. J Clin Periodontol1991; 18: 455-61.

20. Marsh, P.D. Dentifrices containing new agents for the control plaque and gingivitis: microbiological aspects. J Clin Peiodontol 1991; 18: 462-67.

21. Saxton, C.A. The effects of a dentifrices containing zinc citrate and 2.4.4. triclosan-2 hydroydiphenyl ether. J Periodontol, 1986; 57: 555-61. 